\title{
The Present and Future State of Antimicrobial Stewardship and Rapid Diagnostic Testing: Can One Ideally Succeed Without the Other?
}

\section{Kristen Zeitler, BS, PharmD, BCPS ${ }^{1}$}

Navaneeth Narayanan, PharmD, MPH, BCPS ${ }^{2,3, *}$

\author{
Address \\ ${ }^{1}$ Department of Pharmacy, Tampa General Hospital, Tampa, FL, USA \\ *,2Department of Pharmacy Practice, Ernest Mario School of Pharmacy, Rutgers \\ University, 160 Frelinghuysen Road, Piscataway, NJ, 08854, USA \\ Email: navan12@pharmacy.rutgers.edu \\ ${ }^{3}$ Division of Infectious Diseases, Rutgers Robert Wood Johnson Medical School, \\ New Brunswick, NJ, USA
}

Published online: 1 May 2019

(C) The Author(s) 2019

This article is part of the Topical Collection on Antimicrobial Stewardship

Keywords Rapid diagnostics · Molecular diagnostics · Bloodstream infections · Antimicrobial stewardship · Clinical microbiology

\section{Abstract}

Purpose of review The growth and development of rapid diagnostic technologies (RDTs) in infectious diseases (ID) have grown significantly over the past several years. The aim of these platforms is to identify causative pathogens more quickly and target antimicrobial therapy earlier, ultimately improving patient outcomes. Use of RDT specifically from blood specimens to optimize antimicrobial therapy and improve patient outcomes is a recommendation by the most recent antimicrobial stewardship (AMS) guidelines. In this review, we aim to highlight currently available FDA-approved RDTs for clinicians, data supporting the role of blood culture RDT platforms in AMS and their integration into clinical practice with and without AMS support to improve patient outcomes, as well as potential future opportunities for current and pending platforms.

Recent findings New RDT platforms continue to enter the market, most recently with GenMark's ePlex Gram-positive and fungal panels. The Accelerate Pheno ${ }^{\mathrm{TM}}$ technology is unique in its ability to provide identification and phenotypic susceptibility results for pathogens included in its platform within $7 \mathrm{~h}$. We anticipate more RDTs will continue to enter the market in the coming years. Across published literature, it has been shown the most significant impact in optimization of antimicrobial therapy occurs with integration 
of RDT with AMS intervention. Additionally, a recent meta-analysis showed a decreased mortality risk with use of RDT with AMS programs. Despite the perceived benefit of RDT, cost can be a major obstacle for institutions and data on the fiscal impact and associated return on investment are still needed.

Summary Rapid diagnostics in ID and AMS programs continue to grow. Data has shown the benefit of RDTs with AMS intervention, especially in the realm of positive blood cultures. Expansion of RDTs in all culture sites continues to be a need for patients as well as further literature to justify the high costs for these technologies.

\section{Introduction}

Critical illness and its sequelae as a direct result of infection are frequently encountered today within the healthcare system. It is well known that delays in effective antimicrobial initiation significantly impacts survival in adult patients with septic shock, with similar findings demonstrated in cases of pediatric sepsis [1, 2]. A retrospective cohort study of critically ill adult patients with Gram-negative bacteremia highlighted a significant link between initial antibiotic therapy that was inappropriate for the isolated pathogen and hospital mortality [3]. It has also been shown that delayed initiation of antifungal therapy is significantly associated with in-hospital mortality in patients with candidemia [4]. With these data and a plethora of additional literature supporting delays in timely and appropriate antimicrobial therapy negatively impacting patient outcomes, it suggests laboratory technologies aiding in earlier detection of these causative pathogens are needed to improve patient care.

Antimicrobial stewardship (AMS) programs are increasing in recognition, namely due to support through professional organizations such as the Infectious Diseases Society of America (IDSA) and standards implemented by regulatory or accrediting organizations such as The Joint Commission. The 2016 IDSA guidelines, in conjunction with the Society for Healthcare Epidemiology of America, focused on implementation of AMS programs [5]. This publication included recommendations focused on integrating the microbiology laboratory in AMS, specifically related to support for rapid diagnostic testing (RDT) of respiratory viral pathogens as a means to reduce inappropriate antibiotic use as well as utilization of RDT on blood specimens when combined with active AMS support. Collaboration between physician and pharmacist core AMS leaders, microbiology personnel, and primary team members in order to optimize implementation of RDT, reporting, and interpretation of RDT information is essential for these technologies to be effective in optimizing patient care [6].

In this review, we will highlight currently available FDA-approved RDTs for clinicians, data supporting their role in AMS, their integration into AMS programs to improve patient outcomes, as well as potential future opportunities for current and pending platforms.

\section{Types of technology}

The intent of RDTs in the infectious diseases (ID) arena is to identify the causative pathogen(s) quickly in order for clinicians to target antimicrobial therapy and improve clinical outcomes. Traditional pathways for pathogen identification and susceptibility testing may take 48-72 h or longer, depending on the organism and required microbiological work-up by the clinical microbiology laboratory. The current marketplace for RDTs is vast, as evident from Table 1 depicting current FDA-approved available platforms for blood, gastrointestinal (GI), respiratory, and central nervous system (CNS) specimens in the USA. The impact of these technologies for institutional AMS programs is meaningful for all clinical specimen types; 
Table 1. FDA-approved rapid diagnostic platforms

\begin{tabular}{|c|c|c|}
\hline Name of test & Types and targets & Time to result \\
\hline \multicolumn{3}{|l|}{ Blood } \\
\hline MALDI/TOF (Biomerieux, Bruker) & Bacteria, fungi & Variable; at least $30 \mathrm{~min}$ \\
\hline Xpert $^{\circledR}$ MRSA/SA BC (Cepheid) & 1 Gram-positive & $1 \mathrm{~h}$ \\
\hline $\begin{array}{l}\text { FilmArray }{ }^{\circledR} \text { Blood Cultures Identification } \\
\text { (BCID) } \text { (Biofire }^{\circledR} \text { ) }\end{array}$ & $\begin{array}{l}8 \text { Gram-positive } \\
11 \text { Gram-negative } \\
5 \text { yeast } \\
3 \text { resistance genes }\end{array}$ & $1 \mathrm{~h}$ \\
\hline Verigene ${ }^{\circledR}$ Gram-Positive (Luminex ${ }^{\circledR}$ ) & $\begin{array}{l}12 \text { Gram-positive } \\
3 \text { resistance genes }\end{array}$ & $2.5 \mathrm{~h}$ \\
\hline Verigene ${ }^{\circledR}$ Gram-Negative (Luminex ${ }^{\circledR}$ ) & $\begin{array}{l}8 \text { Gram-negative } \\
6 \text { resistance genes }\end{array}$ & $2.5 \mathrm{~h}$ \\
\hline Staphylococcus QuickFISH (OpGen ${ }^{\circledR}$ ) & 2 Gram-positive & $20 \mathrm{~min}$ \\
\hline Enterococcus QuickFISH (0pGen ${ }^{\circledR}$ ) & 3 Gram-positive & $20 \mathrm{~min}$ \\
\hline Gram-Negative QuickFISH (0pGen $\left.{ }^{\circledR}\right)$ & 3 Gram-negative & $20 \mathrm{~min}$ \\
\hline T2Bacteria ${ }^{\circledR}\left(\right.$ T2 Biosystems $\left.{ }^{\circledR}\right)$ & $\begin{array}{l}2 \text { Gram-positive } \\
3 \text { Gram-negative }\end{array}$ & $3-5 h$ \\
\hline T2Candida ${ }^{\circledR}$ (T2 Biosystems ${ }^{\circledR}$ ) & $\begin{array}{l}\text { C. albicans / C. tropicalis } \\
\text { C. glabrata / C. krusei } \\
\text { C. parapsilosis }\end{array}$ & $3-5 h$ \\
\hline $\begin{array}{l}\text { Accelerate Pheno }{ }^{\mathrm{TM}} \\
\text { (Accelerate Diagnostics) }\end{array}$ & $\begin{array}{l}8 \text { Gram-positive } \\
8 \text { Gram-negative } \\
2 \text { yeast }\end{array}$ & $\begin{array}{l}90 \text { min (organism identification); } \\
7 \mathrm{~h} \text { (susceptibility results) }\end{array}$ \\
\hline $\begin{array}{l}\text { GenMark ePlex }^{\circledR} \\
\text { (GenMark Diagnostics, Inc.) }\end{array}$ & $\begin{array}{l}20 \text { Gram-positive } \\
4 \text { Gram-positive resistance genes } \\
15 \text { fungal pathogens }\end{array}$ & $1.5 \mathrm{~h}$ \\
\hline \multicolumn{3}{|l|}{ Gastrointestinal } \\
\hline FilmArray ${ }^{\circledR}$ (Biofire ${ }^{\circledR}$ ) & 22 (bacteria, parasites, viruses) & $1 \mathrm{~h}$ \\
\hline ARIES C. difficile assay (Luminex ${ }^{\circledR}$ ) & 1 (C. difficile) & $2 \mathrm{~h}$ \\
\hline Verigene $^{\circledR}\left(\right.$ Luminex $\left.^{\circledR}\right)$ & $\begin{array}{l}9 \text { (5 bacteria, } 2 \text { toxins, } 2 \text { viruses) } \\
2 \text { (C. difficile toxin } A, B)\end{array}$ & $2 \mathrm{~h}$ \\
\hline xTAG $^{\circledR}\left(\right.$ Luminex $\left.^{\circledR}\right)$ & $\begin{array}{l}14 \text { ( } 8 \text { bacteria/bacterial toxins, } \\
3 \text { viruses, } 3 \text { parasites) }\end{array}$ & $5 \mathrm{~h}$ \\
\hline Xpert ${ }^{\circledR}$ Norovirus (Cepheid ${ }^{\circledR}$ ) & 1 virus & $1 \mathrm{~h}$ \\
\hline Xpert ${ }^{\circledR}$ C. difficile (Cepheid ${ }^{\circledR}$ ) & 1 (C. difficile toxin $\mathrm{B}$ ) & $45 \mathrm{~min}$ \\
\hline Illumigene ${ }^{\circledR}$ (Meridian Bioscience ${ }^{\circledR}$, Inc.) & 1 (C. difficile) & $1 \mathrm{~h}$ \\
\hline Solana (Quidel Corporation) & 1 (C. difficile) & $30 \mathrm{~min}$ \\
\hline BDMAX $^{\mathrm{TM}}$ Cdiff (BD) & 1 (C. difficile toxin B) & $3 \mathrm{~h}$ \\
\hline $\operatorname{BDMax}^{\mathrm{TM}}(\mathrm{BD})$ & $\begin{array}{l}4 \text { bacteria } \\
3 \text { parasites }\end{array}$ & $\begin{array}{l}3 \mathrm{~h} \\
4.5 \mathrm{~h}\end{array}$ \\
\hline \multicolumn{3}{|l|}{ Respiratory } \\
\hline FilmArray ${ }^{\circledR}$ (Biofire ${ }^{\circledR}$ ) & $\begin{array}{l}17 \text { viruses } \\
4 \text { bacteria } \\
\text { (including Bordetella parapertussis) }\end{array}$ & $45-65 \min$ \\
\hline
\end{tabular}


Table 1. (Continued)

\begin{tabular}{|c|c|c|}
\hline Name of test & Types and targets & Time to result \\
\hline ARIES $^{\circledR}\left(\right.$ Luminex $\left.^{\circledR}\right)$ & 3 viruses & $2 \mathrm{~h}$ \\
\hline Verigene ${ }^{\circledR}$ RP Flex Test (Luminex ${ }^{\circledR}$ ) & $\begin{array}{l}13 \text { viruses } \\
3 \text { bacteria }\end{array}$ & $2 \mathrm{~h}$ \\
\hline $\operatorname{NxTAG}^{\circledR}\left(\right.$ Luminex $\left.^{\circledR}\right)$ & $\begin{array}{l}18 \text { viruses } \\
2 \text { bacteria }\end{array}$ & $5 \mathrm{~h}$ \\
\hline $\begin{array}{l}\text { Xpert Xpress Flu/RSV, } \\
\text { Xpress Flu (Cepheid }{ }^{\circledR} \text { ) }\end{array}$ & $\begin{array}{l}3 \text { viruses } \\
2 \text { viruses }\end{array}$ & $20 \mathrm{~min}$ \\
\hline Solana (Quidel Corporation) & $\begin{array}{l}4 \text { viruses (influenza A/B, RSV, hMPV) } \\
\text { Influenza A/B } \\
\text { RSV/hMPV }\end{array}$ & $45 \mathrm{~min}$ \\
\hline $\begin{array}{l}\text { GenMark ePlex }{ }^{\circledR} \\
\text { (GenMark Diagnostics, Inc.) }\end{array}$ & $\begin{array}{l}15 \text { viruses } \\
2 \text { bacterial }\end{array}$ & $1.5 \mathrm{~h}$ \\
\hline \multicolumn{3}{|l|}{ Central nervous system (CNS) } \\
\hline FilmArray ${ }^{\circledR}$ (Biofire) & $\begin{array}{l}6 \text { bacteria } \\
7 \text { viruses } \\
1 \text { yeast }\end{array}$ & $1 \mathrm{~h}$ \\
\hline Xpert ${ }^{\circledR}$ EV $\left(\right.$ Cepheid $\left.^{\circledR}\right)$ & 1 (enterovirus) & $2.5 \mathrm{~h}$ \\
\hline
\end{tabular}

however, significant publications displaying meaningful outcomes have focused on rapid technologies in blood culture specimens. Thus, we will focus on this area moving forward for the remainder of this review.

Each diagnostic platform utilizes differing technology to detect the pathogen(s) of interest and is run on different clinical specimens. Matrix-assisted laser desorption/ionization time-of-flight (MALDI/TOF) is a technology to identify bacterial and fungal pathogens through mass spectrometry after being isolated from a culture colony in a clinical sample. Polymerase chain reaction (PCR) systems, such as the Biofire ${ }^{\circledR}$ Filmarray ${ }^{\circledR}$ and the Cepheid Xpert ${ }^{\circledR}$, nanoparticle particle technology by Verigene ${ }^{\circledR}$ platforms, and peptide nucleic acid fluorescent in situ hybridization (PNA-FISH), an approach used in OpGen ${ }^{\circledR}$ QuickFISH products, are run on positive blood culture specimens. Accelerate Pheno ${ }^{\mathrm{TM}}$ (Accelerate Diagnostics), a novel combination platform for both organism identification and susceptibility testing, as well as the recently approved GenMark ePlex ${ }^{\circledast}$ Gram-positive and fungal panels are also run on positive blood culture isolates. Nuclear magnetic resonance technology is utilized in the T2Candida ${ }^{\circledR}$ and T2Bacteria ${ }^{\circledR}$ panels through T2Biosystems ${ }^{\circledR}$ and can be run on whole blood specimens without requiring an initial signal-positive blood culture. These platforms differ not only in the types of technology they employ but also with respect to the time it takes to result their findings. As shown in Table 1, the time to result for each platform ranges from 20 min to 5 or more hours (depending on identification or susceptibility results).

\section{Impact of RDT on AMS}

AMS is a broad actionable concept defined by various professional organizations, including IDSA, as coordinated interventions designed to improve and 
measure the appropriate use of antibiotic agents by promoting the selection of optimal antibiotic drug regimens including dosing, duration of therapy, and route of administration. The goal of AMS programs is to improve patient outcomes, reduce adverse drug events, reduce incidence of $C$. difficile, and reduce emergence of antibiotic resistance. The utility and benefits of RDT are clearly encompassed in the definition of AMS. The literature demonstrates the association of molecular RDT to identify bacterial pathogens in blood cultures and improvements in time to optimal antibiotic therapy, rate of recurrent infection, mortality, hospital length of stay, and hospital costs. Use of RDT specifically from blood specimens to optimize antibiotic therapy and improve patient outcomes is a recommendation by the most recent IDSA AMS guidelines [5]. Here, we will review representative data on the impact of RDT with and without AMS with a focus on blood specimens.

As new RDTs have emerged, the optimal method of implementation has remained an important question. Various clinical studies have evaluated the impact of various combinations of RDT with or without AMS intervention. An early study by Bauer et al. assessed clinical and economic outcomes of rapid PCR testing for methicillin-resistant Staphylococcus aureus (MRSA)/methicillinsusceptible Staphylococcus aureus (MSSA) from blood cultures. The time to firstline therapy for MSSA bacteremia was faster and hospital costs were less with RDT and ID pharmacist intervention [7]. In the same respect, studies evaluating the impact of rapid identification via MALDI/TOF plus AMS intervention in patients with bacteremia or candidemia have shown benefits in traditional RDT outcomes such as reductions in time to organism identification, time to effective antibiotic therapy, and time to optimal antibiotic therapy as well as hospital length of stay and total hospital costs $[8,9]$. Although it seems intuitive for the need for ID expert support via AMS personnel (e.g., ID pharmacists), a lingering unbiased question remains: would outcomes be similar without AMS involvement?

Although not ideal to maximize benefit of RDT, in resource-limited settings, the benefit of RDT may still be present. Turner et al. conducted a retrospective study comparing standard microbiological identification versus additional use of identification by PCR for $S$. aureus bacteremia without any direct AMS intervention [10]. The investigators observed a statistically significant reduction in time to initiation of optimal therapy but this was only a modest effect and they concluded greater reductions may be possible with direct AMS intervention. A quasi-experimental study by Bhowmick et al. evaluated the impact of RDT for Staphylococcus species (MRSA/MSSA/coagulase-negative staphylococci (CoNS)) with traditional identification methods versus rapid PCR alone versus rapid PCR plus AMS response team intervention [11•]. While time to full identification was drastically reduced with PCR alone, there was only a moderate effect on time to directed therapy. The most significant reduction in time to directed therapy was observed in the final study phase of PCR plus AMS intervention. Here, we observe the natural progression of interventions and their incremental impact with the most benefit noted with RDT plus AMS. Another quasi-experimental study with a broader blood culture identification panel of pathogens and resistance mechanism identification assessed the reverse order of interventions-conventional identification versus conventional identification plus AMS intervention versus rapid multiplex PCR plus AMS intervention [12]. The final intervention group of RDT plus AMS intervention 
had a significantly faster time to effective therapy as compared with the control and AMS-alone groups. Both the AMS alone and RDT plus AMS groups had higher rates of antimicrobial de-escalation as compared with the control but RDT plus AMS had a faster time to de-escalation than both other groups. Through these studies, we observed that RDT alone has only a modest impact on time to optimal therapy, while addition of AMS to RDT or vice versa improves the process measure of time to optimal therapy.

While these studies show a clear signal to the benefit of the combination of RDT and AMS, observational studies have their inherit limitations. Banerjee et al. conducted a randomized, controlled trial assessing outcomes among patients with positive blood cultures [13]. Patients were randomized to standard blood culture processing, rapid multiplex PCR with templated comments, or rapid multiplex PCR with templated comments plus real-time AMS audit and feedback. The use of RDT in this trial significantly improved outcomes (reduced use of broad-spectrum antibiotics and treatment of contaminants) while the addition of AMS further improved time to antimicrobial de-escalation. This study provides highquality evidence consistent with numerous observational studies that note the most significant impact of RDT is in combination with AMS intervention. This is further validated with a recent meta-analysis that assessed the

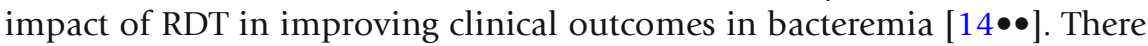
was a decreased mortality risk with use of RDT with AMS programs, while RDT without AMS programs did not show a significant decrease in mortality risk compared with conventional microbiology methods. Having the result in a timely fashion is not enough but rather there is a need for trained clinicians to aid the interpretation and rapid communication to the appropriate prescribers [6].

Many studies regarding molecular RDT methods for identification of the pathogen and genotypic resistance mechanisms have been published over the last decade. On the other hand, data utilizing rapid organism identification and phenotypic antimicrobial susceptibility results, such as Accelerate Pheno ${ }^{\mathrm{Tm}}$, are still emerging. Of note, recently, Henig et al. evaluated the hypothetical impact of Accelerate Pheno ${ }^{\mathrm{TM}}$ on time to effective and definitive therapy in patients with drug-resistant Gram-negative bacteremia [15]. The effect was considered hypothetical because the testing was run in the background of routine clinical care and results were not available to the medical team in real time. Half of the cohort in this study would have had significantly improved time to effective and definitive therapy, even with most patients also receiving testing with Verigene ${ }^{\circledR}$ molecular RDT. Henig et al. conducted an almost identical study but this time included patients with positive blood cultures in general, not only drug-resistant Gram-negative bacteria as previously mentioned [16]. Here, the hypothetical impact on time to effective therapy was extremely minimal, likely due to the baseline use of other molecular RDT methods. Conversely, de-escalation could have been improved by significantly reducing the time to definitive therapy in approximately $30 \%$ of patients. Additionally, usage of certain antibiotics such as cefepime, aminoglycosides, piperacillin/tazobactam, and vancomycin could have decreased with use of Accelerate Pheno ${ }^{\mathrm{TM}}$. In a single-center before-and-after cohort study of actual clinical use, implementation of Accelerate Pheno ${ }^{\mathrm{TM}}$ was associated with shorter time to optimal therapy, 
length of stay, and antibiotic duration of therapy as compared with historical conventional identification (including MALDI/TOF) and antimicrobial susceptibility testing methods [17].

\section{Future state of RDT and AMS incorporating RDT}

The future improvements in the clinical care of patients with infectious diseases that require timely medical care will come from enhanced RDT technology and clinicians' knowledge to act on these rapid results. Thus far, the focus has been on RDT that follows conventional blood culture methods in time sequence. Only after there is a signal-positive blood culture can we put these RDT platforms (e.g., Verigene $^{\circledR}{ }^{\circledR}$ or Accelerate Pheno ${ }^{\mathrm{TM}}$ ) into action for speedy identification and information on resistance. Unfortunately, it may take $24 \mathrm{~h}$ or longer for blood cultures to signal positive, leaving clinicians to make their best guess and patients on empiric therapy during a crucial period in the timeline of critical illness. For over a decade, we have known that for each hour delay in antibiotics there is an increasing risk of mortality for patients with septic shock [1]. Although use of broad-spectrum antibiotics can potentially provide coverage for the causative pathogen, having faster microbiological information to inform targeted antibiotic therapy is the preferred strategy. We acknowledge the importance and utility of numerous rapid syndromic molecular panels for respiratory, GI, and cerebrospinal fluid specimens currently in use as well as future advanced platforms. One example includes the recently FDA-approved PCR-based GenMark ePlex ${ }^{\circledR}$ blood culture identification panels for bacterial and fungal targets from positive blood cultures. Specifically, the Gram-positive and fungal organism panels are FDAapproved while the Gram-negative panel is not yet approved in the USA. These panels are the most comprehensive in terms of the number of targets (e.g., 20 Gram-positive organism targets and 15 fungal organism targets) in addition to resistance gene targets, thereby providing the broadest PCR-based targeted assay yet from positive blood cultures [18]. Here on, we will briefly discuss the first and thus far only pathogen detection test that is done directly from blood without reliance on conventional blood culture results.

The T2Candida ${ }^{\circledR}$ and T2Bacteria ${ }^{\circledR}$ panels are FDA-approved, direct from blood pathogen identification systems for select clinically relevant Candida species and bacterial species, respectively. We'll focus on the T2Candida ${ }^{\circledR}$ given that has been approved and in clinical use for longer and therefore has more data, although this is still limited in breadth. The advantage of this type of technology is there is no delay in waiting for blood cultures to signal positive as well as improved sensitivity and specificity. Recently, Clancy et al. conducted a prospective trial primarily to assess the clinical sensitivity of T2Candida ${ }^{\circledR}$ among hospitalized patients with diagnostic blood cultures indicating candidemia [19•]. Investigators obtained follow-up blood specimens for culture and T2Candida ${ }^{\circledR}$ testing. The T2Can$\operatorname{dida}^{\circledR}$ was sensitive in detecting candidemia. More importantly, it was able to identify Candida species in the follow-up blood specimens that were missed by the companion blood cultures for patients on antifungal therapy. The performance characteristics of this novel assay demonstrate that it may prove valuable in detecting candidemia missed by conventional blood cultures as well as improved sensitivity for patients receiving antifungal therapy. Additionally, a recent study indicates T2Candida ${ }^{\circledR}$ may also be useful in monitoring for clearance of 
candidemia over conventional blood cultures [20]. Further studies, particularly those that include clinical outcomes, are needed before there could be more standardized use for this purpose. Also, having an understanding of which patients should receive this additional direct from blood test (in addition to conventional blood cultures) is not well described. The goal would be to avoid over-testing in patients with limited risk of invasive candidiasis, therefore avoiding a poor positive predictive value and inappropriate testing, and target patients at high risk in order to provide cost-effective care.

Despite the impressive and valuable RDT platforms that have emerged thus far, there are still gaps in technological needs and implementation into clinical practice. Any new technology can be costly; therefore, there is still a gap in the literature on the proven cost-effectiveness of these new platforms. When proposing to include these technologies into the clinical laboratory, administrators will likely need cost-effectiveness data in order to deem it valuable and approve funding. Additionally, there is a need for more data regarding the optimal method of integrating these results into clinical practice and the clinical decision support that AMS programs should be providing. Lastly, much of the data with new emerging RDT platforms such as T2Candida ${ }^{\circledR}$ or T2Bacteria ${ }^{\circledR}$ propose potential benefits for patient outcomes. Small studies indicate that, along with AMS support, T2Candida ${ }^{\circledR}$ may improve time to appropriate antifungal therapy [21]. Large, high-quality clinical studies with meaningful clinical outcomes are needed to better guide implementation and impact and enhance uptake of these newer technologies.

Ideally, RDTs would reach the point where we can have direct rapid identification (e.g., T2 panels), rapid and accurate phenotypic antimicrobial susceptibility testing (e.g., Accelerate Pheno ${ }^{\mathrm{TM}}$ ), a fully encompassing list of clinically relevant target pathogens (i.e., bacterial, fungal, viral) for detection, and distinction between true pathogen versus contamination or colonization. If clinicians had a direct from blood (or any specimen) test where we could know the full identification and antimicrobial susceptibility for any pathogen within an hour, this would have the capability to eliminate both under- and overtreatment of patients with sepsis and other non-specific infectious syndromes receiving empiric rather than definitive therapy. This hypothetical future state would likely need trained expertise from AMS physicians and pharmacists as well as clinical microbiologists to aid in implementation, interpretation of results, and clinical decision support regarding appropriate antimicrobial use.

Moving forward, we believe the value of RDT, particularly with integration into AMS programs, will be more widely realized and it will be utilized in more clinical settings ranging from academic medical centers to small community hospitals. RDT should become standard of care in conjunction with current standard conventional microbiological testing methods and AMS practices given the potential for significant improvement in patient outcomes and healthcare cost savings. In order to reach this point, more data will be necessary to prove the cost-effectiveness and clinical quality impact of various RDT platforms.

\section{Conclusions}

In the field of ID, RDTs are ever increasing and continue to be a game changer for healthcare. The data and years of clinical experience have shown high 
mortality rates for patients when antimicrobials are not started in a timely manner as well as when initial therapy is inappropriate for critically ill patients. As technology in this field evolves, there is a need for these platforms to continue to develop for all culture sites so we can optimize outcomes for patients with a multitude of infectious conditions outside bloodstream infections. It remains part of the core AMS practice to optimize therapy in a timely manner and these technologies should be integrated into the daily workflow to assist us with patient care. Moving forward, more high-quality literature on emerging RDT platforms is needed to support their integration with AMS, demonstrate the associated clinical impact on patient outcomes as well as the cost-effectiveness of RDT integration with AMS. We recognize the concern with overall cost of these platforms; thus, future studies should continue to evaluate the economic impact of RDT at both the patient and health system level.

\section{Acknowledgements}

The authors would like to acknowledge Suzane Silbert, PhD, Scientific Director of Esoteric/R\&D and Microbiology Laboratories at Tampa General Hospital, for her knowledge and insight into rapid diagnostic platforms.

\section{Compliance with Ethical Standards}

\section{Conflict of Interest}

Kristen Zeitler declares that she has no conflict of interest. Navaneeth Narayanan declares that he has no conflict of interest.

\section{Human and Animal Rights and Informed Consent}

This article does not contain any studies with human or animal subjects performed by any of the authors.

Open Access This article is distributed under the terms of the Creative Commons Attribution 4.0 International License (http://creativecommons.org/licenses/by/4.0/), which permits unrestricted use, distribution, and reproduction in any medium, provided you give appropriate credit to the original author(s) and the source, provide a link to the Creative Commons license, and indicate if changes were made.

\section{References and Recommended Reading}

Papers of particular interest, published recently, have been highlighted as:

- Of importance

- Of major importance

1. Kumar A, Roberts D, Wood KE, Light B, Parrillo JE, Sharma S, et al. Duration of hypotension before initiation of effective antimicrobial therapy is the critical determinant of survival in human septic shock. Crit Care Med. 2006;34(6):1589-96. https://doi.org/10. 1097/01.CCM.0000217961.75225.E9.
2. Weiss SL, Fitzgerald JC, Balamuth F, Alpern ER, Lavelle J, Chilutti M, et al. Delayed antimicrobial therapy increases mortality and organ dysfunction duration in pediatric sepsis. Crit Care Med. 2014;42(11):2409-17. https://doi.org/10.1097/ CCM.0000000000000509. 
3. Zilberberg MD, Shorr AF, Micek ST, Vazquez-Guillamet $\mathrm{C}$, Kollef MH. Multi-drug resistance, inappropriate initial antibiotic therapy and mortality in Gram-negative severe sepsis and septic shock: a retrospective cohort study. Crit Care. 2014;18(6):596. https://doi.org/10. 1186/s13054-014-0596-8.

4. Morrell M, Fraser VJ, Kollef MH. Delaying the empiric treatment of candida bloodstream infection until positive blood culture results are obtained: a potential risk factor for hospital mortality. Antimicrob Agents Chemother. 2005;49(9):3640-5. https://doi.org/10. 1128/AAC.49.9.3640-3645.2005.

5. Barlam TF, Cosgrove SE, Abbo LM, MacDougall C, Schuetz AN, Septimus EJ, et al. Implementing an Antibiotic Stewardship Program: guidelines by the Infectious Diseases Society of America and the Society for Healthcare Epidemiology of America. Clin Infect Dis. 2016;62(10):e51-77. https://doi.org/10.1093/cid/ ciw118.

6. Hill B, Narayanan N, Palavecino E, Perez KK, Premraj S, Streifel A, et al. The role of an antimicrobial stewardship team in the use of rapid diagnostic testing in acute care: an official position statement of the Society of Infectious Diseases Pharmacists. Infect Control Hosp Epidemiol. 2018;39(4):473-5. https://doi.org/10. 1017/ice.2018.11

7. Bauer KA, West JE, Balada-Llasat JM, Pancholi P, Stevenson KB, Goff DA. An antimicrobial stewardship program's impact with rapid polymerase chain reaction methicillin-resistant Staphylococcus aureus/S. aureus blood culture test in patients with $\mathrm{S}$. aureus bacteremia. Clin Infect Dis. 2010;51(9):1074-80. https:// doi.org/10.1086/656623.

8. Perez KK, Olsen RJ, Musick WL, Cernoch PL, Davis JR, Land GA, et al. Integrating rapid pathogen identification and antimicrobial stewardship significantly decreases hospital costs. Arch Pathol Lab Med. 2013;137(9):1247-54. https://doi.org/10.5858/arpa. 2012-0651-OA.

9. Huang AM, Newton D, Kunapuli A, Gandhi TN, Washer LL, Isip J, et al. Impact of rapid organism identification via matrix-assisted laser desorption/ ionization time-of-flight combined with antimicrobial stewardship team intervention in adult patients with bacteremia and candidemia. Clin Infect Dis. 2013;57(9):1237-45. https://doi.org/10.1093/cid/ cit498.

10. Turner RB, Lalikian K, Fry M, Schwartz J, Chan D, Won R. Impact of rapid identification of Staphylococcus aureus bloodstream infection without antimicrobial stewardship intervention on antibiotic optimization and clinical outcomes. Diagn Microbiol Infect Dis. 2017;89(2):125-30. https://doi.org/10.1016/j. diagmicrobio.2017.07.003.

11. Bhowmick T, Kirn TJ, Hetherington F, Takavarasha S, Sandhu SS, Gandhi S, et al. Collaboration between an antimicrobial stewardship team and the microbiology laboratory can shorten time to directed antibiotic therapy for methicillin-susceptible staphylococcal bacteremia and to discontinuation of antibiotics for coagulase-negative staphylococcal contaminants. Diagn Microbiol Infect Dis. 2018. https://doi.org/10. 1016/j.diagmicrobio.2018.05.020

This study found implementation of rapid diagnostic testing resulted in reductions in median time to identification of coagulase-negative Staphylococci and methicillin-susceptible Staphylococcus aureus, along with statistically significant reductions in median time to directed therapy for both pathogens when antimicrobial stewardship intervention was coupled with rapid diagnostics.

12. MacVane SH, Nolte FS. Benefits of adding a rapid PCRbased blood culture identification panel to an established antimicrobial stewardship program. J Clin Microbiol. 2016;54(10):2455-63. https://doi.org/10. 1128/JCM.00996-16.

13. Banerjee R, Teng CB, Cunningham SA, Ihde SM, Steckelberg JM, Moriarty JP, et al. Randomized trial of rapid multiplex polymerase chain reaction-based blood culture identification and susceptibility testing. Clin Infect Dis. 2015;61(7):1071-80. https://doi.org/ $10.1093 / \mathrm{cid} / \mathrm{civ} 447$.

14.• Timbrook TT, Morton JB, McConeghy KW, Caffrey AR, Mylonakis E, LaPlante KL. The effect of molecular rapid diagnostic testing on clinical outcomes in bloodstream infections: a systematic review and meta-analysis. Clin Infect Dis. 2017;64(1):15-23. https://doi.org/10. 1093/cid/ciw649

In this systematic review and meta-analysis, mortality risk was significantly lower with molecular rapid diagnostic testing (compared with traditional microbiology methods) and antimicrobial stewardship involvement for patients with bloodstream infections; however, this mortality risk was lower but not significantly different when antimicrobial stewardship was not involved.

15. Henig O, Kaye KS, Chandramohan S, Cooper CC, Lephart $\mathrm{P}$, Salimnia H, et al. The hypothetical impact of Accelerate Pheno (ACC) on time to effective therapy and time to definitive therapy for bloodstream infections due to drug-resistant Gram-negative bacilli. Antimicrob Agents Chemother. 2018;63. https://doi. org/10.1128/AAC.01477-18.

16. Henig O, Cooper CC, Kaye KS, Lephart P, Salimnia H, Taylor $\mathrm{M}$, et al. The hypothetical impact of Accelerate Pheno system on time to effective therapy and time to definitive therapy in an institution with an established antimicrobial stewardship programme currently utilizing rapid genotypic organism/resistance marker identification. J Antimicrob Chemother. 2019;74(Supplement_1):i32-i9. https://doi.org/10. 1093/jac/dky533.

17. Dare R, McCain K, Lusardi K, Daniels K, Painter J, Lakkad M, et al. Impact of Accelerate Pheno rapid blood culture detection system on laboratory and clinical outcomes in bacteremic patients. Open Forum Infect Dis. 2018;5(suppl_1):S61.

18. Huang TD, Melnik E, Bogaerts P, Evrard S, Glupczynski Y. Evaluation of the ePlex blood culture identification panels for detection of pathogens in bloodstream 
infections. J Clin Microbiol. 2018;57. https://doi.org/ 10.1128/JCM.01597-18.

19.• Clancy CJ, Pappas PG, Vazquez J, Judson MA, Kontoyiannis DP, Thompson GR 3rd, et al. Detecting Infections Rapidly and Easily for Candidemia Trial, Part 2 (DIRECT2): a prospective, multicenter study of the T2Candida panel. Clin Infect Dis.

2018;66(11):1678-86. https://doi.org/10.1093/cid/ cix1095

This study highlights the sensitivity of the T2Candida panel in aiding to diagnose candidemia, including in patients who received previous antifungal therapy.

20. Mylonakis E, Zacharioudakis IM, Clancy CJ, Nguyen MH, Pappas PG. Efficacy of T2 magnetic resonance assay in monitoring candidemia after initiation of antifungal therapy: the Serial Therapeutic and Antifungal
Monitoring Protocol (STAMP) trial. J Clin Microbiol. 2018;56(4). https://doi.org/10.1128/JCM.01756-17.

21. Wilson NMAG, Ribbetts RJ, Samuel LP, Davis SL, Kenney RM. T2 magnetic resonance assay improves timely management of candidemia. JAMS.

2017;1(1):12-8.

\section{Publisher's Note}

Springer Nature remains neutral with regard to jurisdictional claims in published maps and institutional affiliations. 